\title{
A numerical analysis of a HYBRID PV+WT power system
}

\author{
Marek Jaszczur ${ }^{1, *}$, Qusay Hassan ${ }^{2}$, Haidar N. Al-Anbagi ${ }^{3}$ and Patryk Palej ${ }^{1}$ \\ ${ }^{1}$ AGH University of Science and Technology, Department of Fuels and Energy, Poland \\ ${ }^{2}$ University of Diyala, Department of Mechanical Engineering, Iraq \\ ${ }^{3}$ University of Diyala, Department of Communications Engineering, Iraq
}

\begin{abstract}
The increase in global energy consumption and the expected exhaustion of traditional energy sources, especially in the last century, led to an increased search for alternative sources of energy. The use of renewable energy sources has become extremely important to reduce dependence on fossil fuels. Due to the stochastic nature of the renewable energy sources such as the wind speed fluctuation and the intensity of solar radiation the stable operation of the systems base single renewable source can be problematic. But the using two or more of these sources results in higher stability than relying on a single source. For this reason, hybrid renewable energy systems have become an attractive solution in the field of renewable energy. A hybrid energy system is a combination of two or more renewable energy sources that can enhance each another to increase the reliability of the supplied energy. The objective of this paper is investigation about the energy supplying improvement and the energy efficiency utilisation by hybridisation using two renewable energy resources: wind energy and solar energy with respect two different optimisation objectives: economical to reduce the net present cost and ecological to reduce $\mathrm{CO}_{2}$ emissions. Presented system has been implemented to supply a single household with an electric load.
\end{abstract}

\section{Introduction}

Electric energy is an essential form of energy that has an essential role in human life and industrial growth. Fossil fuel resources deployment has a significant effect on power generation. It is required to be gradually replaced by renewable energy, which is permanent [1]. The renewable energy resource stochastic nature may not provide a stable, continuous and reliable energy supply. For energy efficiency improving, stability improving, increase capacity and utilisation factor, one or more renewable energy resources have to be used in the form of hybrid configuration.

Renewable energy resources hybridisation become a critical issue of utilisation increase, to gain exergetic and energetic efficiencies of the energy conversion and systems stability. The integration of the energy systems is through sources, spatial or temporal, to increase the utilisation factor, enhance the security of energy supplies as well as to reduce capital and operating costs of the equipment [2].

Hybridisation involves various renewable energy resources such as solar, photovoltaic, wind, etc., and can be integrated with conventional energy systems to fully supply consumer loads. These energy hybrids face complexities arising from the diverse nature of renewable energy sources, intermittent availability, low energy density, and random elements. The recent developments in the energy processing, monitoring and management enable the stable operation of integrated systems to support renewable resources of energy. It can represent supplies of solar, wind in terms of random and segmental components. Solar energy may follow a similar profile during the day but does not supply during the night. The wind is more random and very seasonal. Globally, there are several research groups that has been analysed and modelled Hybrid Renewable Energy Systems (HRES) for different sites of the world. An excellent review for hybrid renewable energy system utilisation has been written by Jahangiri et al. [3] and Guo et al. [4].

Kerdphol et al. [5] optimise HRES at the technical objective of optimisation by using search-based methods methodology at two optimisation algorithms (analytical method and of particle swarm optimisation method). The analysed system consists of PV, battery and hydropower connected to the gird. The results show that while minimising the battery size for load shedding, the optimal system configuration predicted by using particle swarm optimisation is better than the analytical method. Ceran et al. [6] have been modelled HRES composed of a PV module, wind turbine, an electrolyser, and fuel cells with the hydrogen tank for energy supply to the single household in Poznan city, Poland. The results

\footnotetext{
*Corresponding author: jaszczur@agh.edu.pl
} 
show that the energy supplied from HRES can serve the household energy consumption for three days during cloudy weather. Palej et al. [7] have been analysed PV/Wind/Grid-on HRES under different operating conditions to study the environmental and economic feasibility for energy supply to electrify a single household. The results showed that the optimal configuration of HRES based on the economic objective presents the best compromise for the system components and lowest cost of energy and at the same time the environmental objective offers achieves a higher cost of energy than economic objective but also much higher $\mathrm{CO}_{2}$ production avoidance. Hassan et al. [8-11] studied solar energy and performed HRES analysis. Authors investigated renewable energy resources for a higher and more reliable energy system supplier for the rural village in Iraq. Jaszczur et al. [12-14] has modelled HRES for typical household energy consumption for two different objectives. In addition, authors investigated the effect of natural dust deposition on PV solar energy systems [1517]. The results show the energy power degradation due to dust deposition and a new model that can predict the derating factor for PV module due to natural dust deposition was presented.

Huang et al. [18] presented a quite different approach. Authors idea was to build a multi-turbine system which consists of several small wind turbines placed on a single tower. System would be also connected with solar panels. Power of the proposed system was $60 \mathrm{~kW}$. Nguyen et al. [19] have modelled HRES consist of $15 \mathrm{~kW}_{\mathrm{p}}$ PV, $8 \mathrm{~kW}$ diesel generator, and vanadium redox battery (VRB). The results illustrated that the battery rated $65 \mathrm{kWh} / 5 \mathrm{~kW}$ for the islanded mode and $5 \mathrm{kWh} / 5 \mathrm{~kW}$ for the grid-connected mode that can achieve the minimum net present cost for the system. Bahmani et al. [20] designed and analysed HRES consists of micro-turbine, fuel cell, PV, wind turbine, Liion battery at the financial indicator by using searchbased methods for component sizing. The study was performed by minimising the total cost. The results showed that the level of initial battery charge could lead to a significant difference in the battery sizes from 150 $\mathrm{kWh}$ to $250 \mathrm{kWh} / 30 \mathrm{~kW}$. In a study done by Chen et al. [21] the economic optimisation was selected as an objective for HRES with different components: wind turbine, PV, battery, micro-turbine and fuel cell. In the grid-connected case, the system components were operated at mode able to maximise total benefit and in the islanded mode able to minimise the total cost.

Abbey et al. [22] analysed HRES system composed of wind turbine, diesel generator and battery and optimised system based on the economical objective. The results show that energy production and power capacity of the system obtained significant differences ranging among different scenarios for the lowest operation cost or lower capital cost. In [23] authors compared different meteorological sites distributed in Afghanistan and analysed the available data. The data contained solar radiation intensity and wind speed and the authors mapped all the information to the specific place. Borowy and Salameh, investigate the optimum photovoltaic array size for a hybrid system [24]. In this analysis very long term data of irradiance and wind speed recorded for every hour of the day for 30 years were used. Kruangpradit [25] describes the Programme for Environmental Awareness (PEA) on design, implementation and evaluation of pilot HRES for electrification of remote villages in Thailand. Two combinations proposed PV/Microhydro/Diesel/Battery system and PV/Diesel/Battery and PV system gridconnected. Ottoson et al. [26] investigated the performance of HRES for rural site based on PV, WT and diesel components by using data logger for an exhaustive analysis of system performance and energy production. A new system has been developed by Nogaret et al. [27] based on control tool for HRES and consist of PV and WT. Presented tool can be used for advanced control of HRES and optimal operation.

The main objective of this work is to analyse and optimize HRES conceded with the grid consisting of solar panels and wind turbines. The optimisation is multi-objective, and the objectives are: minimising total Net Present Cost (NPC) and minimising total $\mathrm{CO}_{2}$ emission.

\section{System modelling and description}

The system composed of 4 main parts. Main parts are PV panels, wind turbines, a batteries and grid system. Components are able to generate or delivery electric power in cogeneration. An advantage of such a combination is that in case of lack in solar radiation or wind, the system still can obtain the energy with constant required by the device's parameters. Altogether they generate power for the residential load. Because the solar panel produces DC power, there is a need for inverter between PV and AC line. In addition to controlling the amount of power generated by the components, there are controllers which can distribute power demand between the solar panel, wind turbine and the grid system. Schematic view of the hybrid renewable energy system is presented in Figure 1.

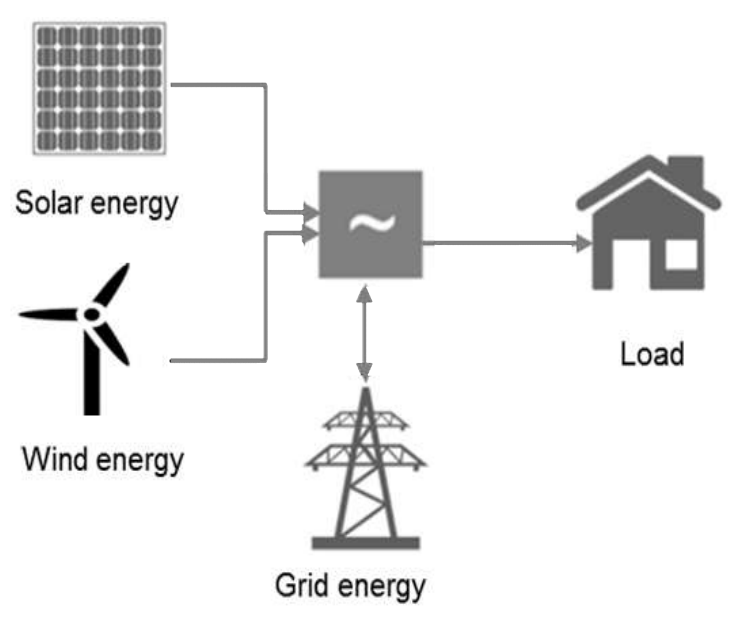

Fig. 1. Hybrid renewable energy system - schematic diagram.

The HRES system simultaneous power generation can be described by the equation: 


$$
P_{h, t}=P_{W T, t}+P_{P V, t}+P_{b, t}+P_{G r i d, t}
$$

where $P_{h, t}$ is the simultaneous power of the hybrid system, $P_{W T, t}$ is the simultaneous power generated by a wind turbines components and $P_{P V, t}$ is the simultaneous power generated by PV panels. The $P_{P V}$ power generated by the photovoltaic panel can be calculated as follows [14]:

$$
P_{P V}=C_{P V} \eta_{P V}\left(\frac{G_{T}}{G_{T, S T C}}\right)\left[1+\alpha_{P}\left(T_{c}-T_{c, S T C}\right)\right]
$$

where: $C_{P V}$ rated capacity of the PV array; $\eta_{P V}$ is $\mathrm{PV}$ derating factor; $G_{T}$ incident solar radiation, $\alpha_{p}$ temperature coefficient of power; $T_{c}$ temperature of the cell and STC refers to Standard Temperature Conditions.

Wind turbine power $P_{W T}$ can be calculated using the following equation [11]:

$$
P_{W T}=P_{s t} \cdot \frac{\rho_{r}}{\rho_{o}}
$$

where: $P_{s t}$ is power under standard conditions; $\rho_{r}$ real density; $\rho_{o}$ density under standard condition.

Power from the grid (or to the grid) is a difference between the power demand and energy production rate from the PV panels and wind turbines. If the energy production rate exceeds power demand, the surplus energy is transmitted to the grid. Therefore, the grid system can be used not only as a source of energy but also as energy storage.

The optimisation, to be done has two different criteria. One of them is minimising the total Net Present Cost. Therefore, the cost of energy also decreases. Cost of energy (COE) can be calculated from the following formula:

$$
C O E=\frac{C_{a n n, t o t}}{E_{p r i m, A C, D C}+E_{\text {grid,sales }}}
$$

where $E_{\text {prim, } A C D C}$ is the AC and DC primary load served, $E_{\text {grid,sales }}$ is the total grid sales and $C_{\text {ann,tot }}$ is the total annualised cost of the system that includes the annualised costs of each system component. Net Present Cost can be calculated from the equation:

$$
C_{N P C}=\frac{C_{a n n, t o t}}{C R F\left(i, R_{p r o j}\right)}
$$

where $C R F$ is the capital recovery factor calculated from the following equation:

$$
C R F(i, N)=\frac{i(1+i)^{N}}{(1+i)^{N}-1}
$$

where $i$ stands for interest rate and $N$ is the number of years of the system exploitation.

The amount of $\mathrm{CO}_{2}$ emissions generated due to the energy taken from the grid and emissions due to the manufacturing process can be described as follows:

$$
\mathrm{HRES}_{\mathrm{CO}_{2}}=\mathrm{PV}_{\mathrm{CO}_{2}}+W \mathrm{WT}_{\mathrm{CO}_{2}}+\text { Battery }_{\mathrm{CO}_{2}}+\text { Inverter }_{\mathrm{CO}_{2}}+\text { Grid }_{\mathrm{CO}_{2}}
$$

where: $\mathrm{HRES}_{\mathrm{CO} 2}$ - total $\mathrm{CO}_{2}$ emissions generated for HRES; $P_{C O 2}$ is the $\mathrm{CO}_{2}$ emissions generated due to manufacturing process of $\mathrm{PV}$ component; $W T_{\mathrm{CO} 2}$ is the $\mathrm{CO}_{2}$ emissions generated due to manufacturing process of WT component, Battery ${ }_{\mathrm{CO} 2}$ is the $\mathrm{CO}_{2}$ emissions generated due to manufacturing process of battery and Gridco2 is the $\mathrm{CO}_{2}$ emissions generated due energy taken from the grid system.

The primary (due to manufacturing process) emissions for the renewable energy components was: PV is $800 \mathrm{~kg} / \mathrm{kW}_{\mathrm{p}}$, WT is $300 \mathrm{~kg} / \mathrm{kW}$, inverter is $60 \mathrm{~kg} / \mathrm{kW}$, battery is $55 \mathrm{~kg} / \mathrm{kWh}$ and based on energy taken from the grid is $0.867 \mathrm{~kg} / \mathrm{kWh}$. The component specifications is as follows: wind turbine: (Aelos- $\mathrm{H}$ size: $1.0 \mathrm{~kW} \mathrm{AC}$; cost $350 €$; lifetime $25 \mathrm{yr}$ ) [28], photovoltaic module: (Schott ASI200; size: $200 \mathrm{Wp}$; cost: $220 €$; lifetime: 25 yr) [29] inverter: (Generic:1200CH; size: 1200VA; cost:000€ ; lifetime: $10 \mathrm{yr}$ [ [30].

\section{Experimental data}

3.1 Load demand: The electrical load based on experimental measurement for a household in Krakow, Poland acquired at one-minute time step resolution for the period of 01.01 .2017 , to 31.12 .2017 . The daily electrical load distribution on selected days (17.08.2017 and 07.01.2017) and the monthly energy consumption are presented in Figure 2(a)-(b), respectively.
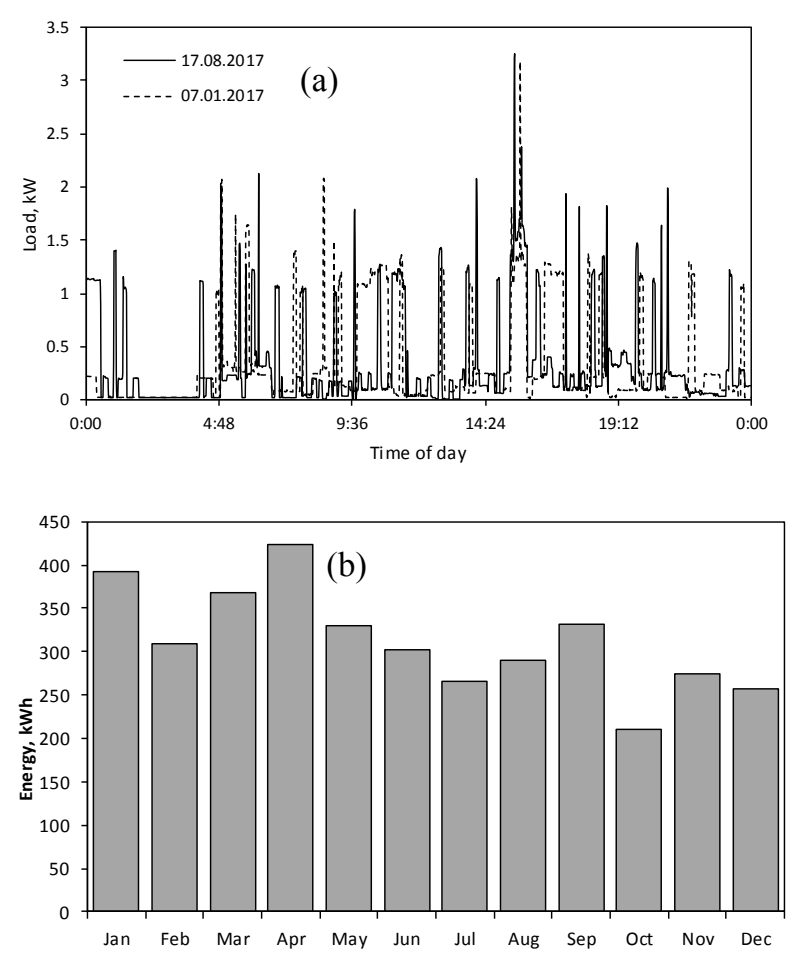

Fig. 2. The daily electrical load for two selected days during the winter and summer(a) and monthly energy consumption(b).

3.2 Wind speed and ambient: The weather data (wind speed and ambient temperature) has been acquired from the weather meters (Anemometer \& Thermometer) 
located at AGH University of Science and Technology campus, for the period 01.01.2017-31.12.017. The measured was done with 5 minutes' time step resolution. The monthly average for both parameters are presented in Figure 3.

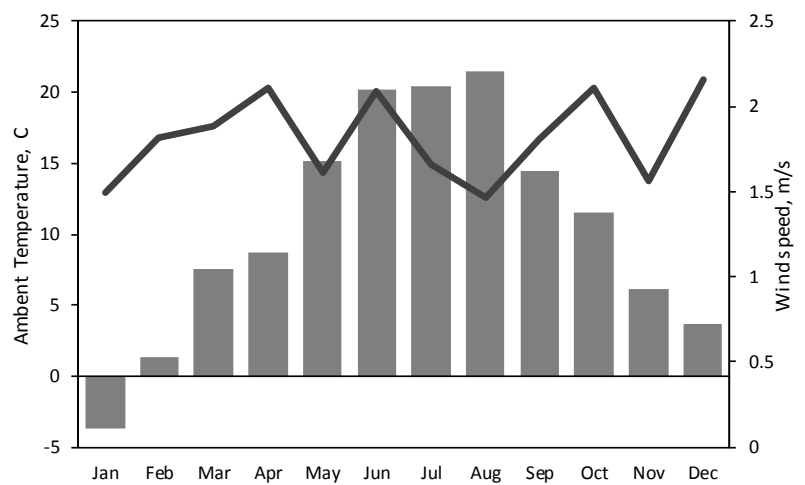

Fig. 3. Monthly average of the wind speed and ambient temperature.

3.3 Solar radiation: the global incident solar radiation were measured from 01.01.2017 to 31.12.2017 at the AGH University of Science and Technology campus in Kraków, Poland (50.066354N, 19.918191E) as showed for 2 days (winter on 27.02.2017 and summer on 20.06.2017) in Figure 4(a) and the monthly average in Figure 4(b).
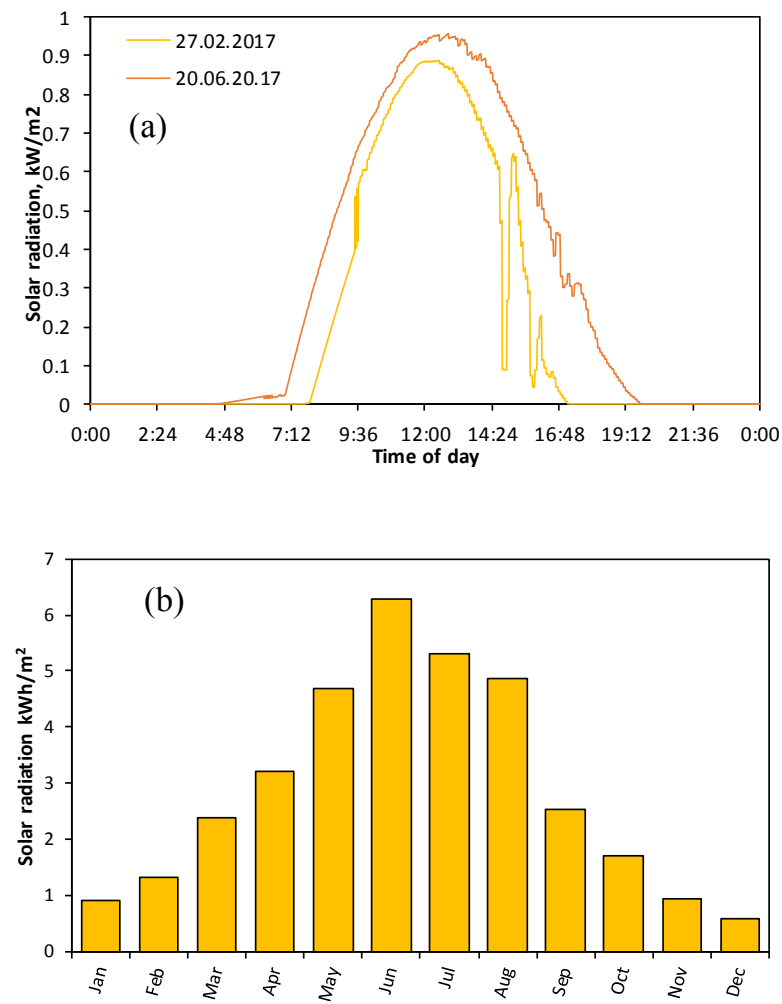

Fig. 4. The total solar radiation distribution: instantaneous for selected days (a) and monthly averaged solar radiation (b).

\section{Results and discussions}

The analysis performed based on the experimental measurements of electrical load, wind speed, ambient temperature and solar irradiation. Table 1 shows the first 5 best configurations for HRES configuration based on the economical objective of optimisation (minimise NPC and $\mathrm{COE}$ ).

Table 1. Optimum HRES configuration based on economical optimization objective

\begin{tabular}{|c|c|c|c|c|c|c|c|}
\hline No. & NPC $(\boldsymbol{\epsilon})$ & $\begin{array}{c}\mathbf{C O E} \\
(\boldsymbol{\epsilon})\end{array}$ & $\begin{array}{c}\mathbf{C O}_{2} \\
(\mathbf{k g} / \mathbf{y r})\end{array}$ & $\begin{array}{c}\mathbf{P V} \\
(\mathbf{k W})\end{array}$ & $\begin{array}{c}\mathbf{W T} \\
(\mathbf{k W})\end{array}$ & $\begin{array}{c}\text { Renewable } \\
\text { energy } \\
(\mathbf{k W h} / \mathbf{y r})\end{array}$ & $\begin{array}{c}\text { Excess } \\
(\mathbf{k W h} / \mathbf{y r})\end{array}$ \\
\hline $\mathbf{1}$ & $\mathbf{2 8 2 6 7 . 2 8}$ & 0.3 & 2263.12 & 4.2 & 1.26 & 4374 & 2775 \\
\hline $\mathbf{2}$ & $\mathbf{2 8 4 2 8 . 8 8}$ & 0.3 & 2255.49 & 4.2 & 2.57 & 4500 & 2856 \\
\hline $\mathbf{3}$ & $\mathbf{2 8 6 3 6 . 9 3}$ & 0.31 & 2249.64 & 4.5 & 1.26 & 4673 & 3045 \\
\hline $\mathbf{4}$ & $\mathbf{2 8 8 0 1 . 1 9}$ & 0.31 & 2242.84 & 4.5 & 2.57 & 4798 & 3127 \\
\hline $\mathbf{5}$ & $\mathbf{2 9 0 1 2 . 2 2}$ & 0.31 & 2237.88 & 4.8 & 1.26 & 4971 & 3317 \\
\hline
\end{tabular}

Table 2 shows the first 5 best configurations for HRES configuration based on the ecological objective of optimisation (minimise $\mathrm{CO}_{2}$ emissions)

Table 2. Optimum HRES configuration based on ecological optimisation objective

\begin{tabular}{|c|c|c|c|c|c|c|c|}
\hline No. & $\mathbf{N P C}(\boldsymbol{\epsilon})$ & $\begin{array}{c}\mathbf{C O E} \\
(\boldsymbol{\epsilon})\end{array}$ & $\begin{array}{c}\mathbf{C O}_{2} \\
(\mathbf{k g} / \mathbf{y r})\end{array}$ & $\begin{array}{c}\mathbf{P V} \\
(\mathbf{k W})\end{array}$ & $\begin{array}{c}\mathbf{W T} \\
(\mathbf{k W})\end{array}$ & $\begin{array}{c}\text { Renewable } \\
\mathbf{e n e r g y} \\
(\mathbf{k W h} / \mathbf{y r})\end{array}$ & $\begin{array}{c}\mathbf{E x c e s s} \\
(\mathbf{k W h} / \mathbf{y r})\end{array}$ \\
\hline 1 & 42267.7 & 0.45 & $\mathbf{2 1 3 1 . 1}$ & 7.2 & 11.34 & 8895 & 6924 \\
\hline 2 & 40980.9 & 0.44 & $\mathbf{2 1 5 1 . 2}$ & 7.2 & 10.08 & 8704 & 6748 \\
\hline 3 & 39697.3 & 0.42 & $\mathbf{2 1 6 2 . 3}$ & 7.2 & 8.82 & 8512 & 6570 \\
\hline 4 & 38420.3 & 0.41 & $\mathbf{2 1 7 5 . 3}$ & 7.2 & 7.56 & 8320 & 6394 \\
\hline 5 & 37149.07 & 0.4 & $\mathbf{2 1 8 0 . 1}$ & 7.2 & 6.3 & 8128 & 6218 \\
\hline
\end{tabular}

The daily distribution of energy production for a single arbitrary selected day (30.07.2017) at economical and environmental objectives have been presented in Table 3.

Table 3. The energy flows for the single selected day (28.03.2017)

\begin{tabular}{|c|c|c|c|c|c|}
\hline $\begin{array}{c}\text { Optimisation } \\
\text { objective }\end{array}$ & $\begin{array}{c}\text { AC load } \\
(\mathrm{kWh})\end{array}$ & $\begin{array}{c}\text { PV } \\
\text { energy } \\
(\mathrm{kWh})\end{array}$ & $\begin{array}{c}\text { WT } \\
\text { energy } \\
\text { (kWh) }\end{array}$ & \begin{tabular}{|c|} 
Energy \\
from grid \\
$(\mathrm{kWh})$
\end{tabular} & $\begin{array}{l}\text { Energy } \\
\text { fed grid } \\
(\mathrm{kWh})\end{array}$ \\
\hline NPC & \multirow{2}{*}{11.94} & 22.81 & 0.50 & 10.05 & 19.15 \\
\hline $\mathrm{CO}_{2}$ & & 39.11 & 4.53 & 9.83 & 36.70 \\
\hline
\end{tabular}

Figures 5(a) and 5(b) the daily distributed power for a sunny day (28.03.2017) at economical optimisation objective and environmental optimisation objective are shown respectively. It is very clear from those figures that the HRES at environmental optimisation objective has higher renewable energy than economical optimisation objectives which can deliver to the grid. Table 3 shows the daily energy flows distribution for 30.07.2017. The wind turbine units have low energy generated in the selected site for poor wind speed while solar energy is the higher.

Figure 6 shows the monthly energy distribution (taken from the grid and feed to the grid) based on two optimisation objectives. The highest energy flow which feeds to the grid at the environmental objective is due to the largest renewable energy components sizes. 

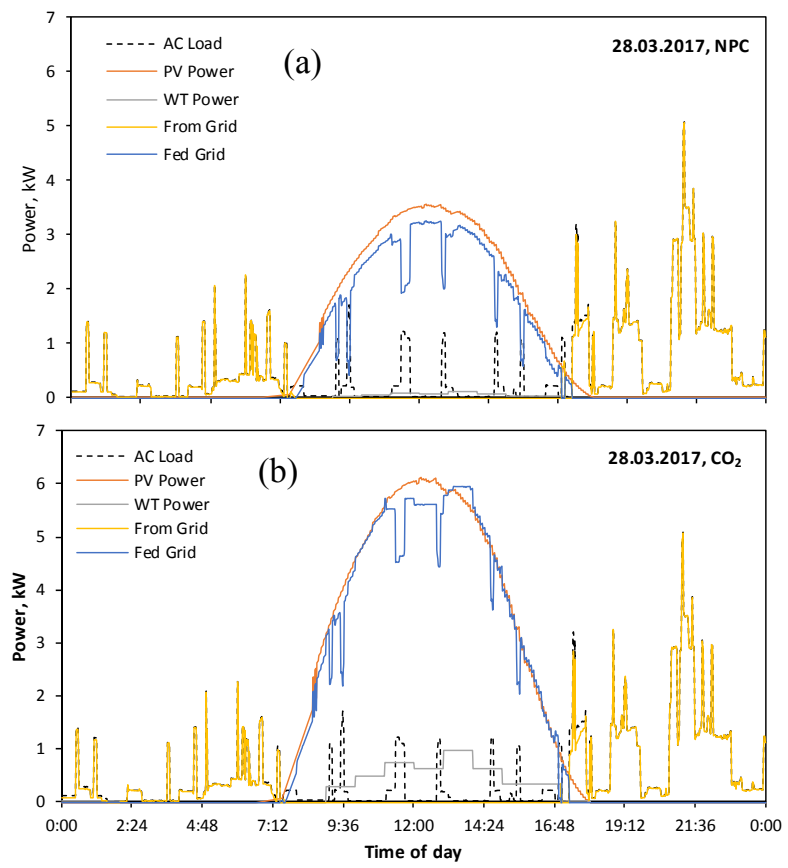

Fig. 5. The daily distributed power for a sunny day (28.03.2017) at economical optimisation objective (a) and environmental optimisation objective (b)
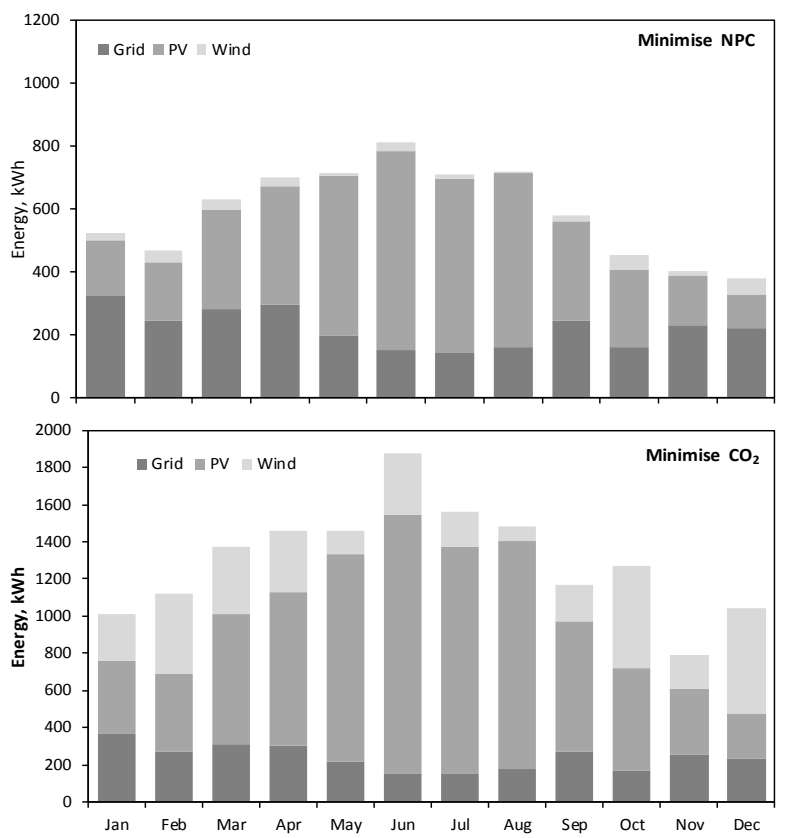

Fig. 6. Monthly energy distribution for economical and environmental objectives

\section{Conclusions}

Integrating an individual renewable energy system with the grid for supplying energy to a single household indicted high power reliability. This work evaluates the performance of HRES composed of PV and WT connected to the grid at environmental and economic objectives. The analysis has been evaluated based on the measured experimental data.

A comprehensive simulation has been developed to analyse the relationship between economic and environmental aspects. For both objectives, the best five configurations have been presented. Simulations show that during the day energy production may be higher than power demand and the excess energy is transmitted to the grid. During the night power generation decreases, so it is being taken from the grid. Results show that economic objective is the most important criteria and should be considered as a primary objective while an environmental one has a secondary importance.

ACKNOWLEDGEMENT. This work was partially supported by the Polish Ministry of Science (Grant AGH No. 16.16.210.476).

\section{References}

1. J. Lew, D. Barley, T. Flowers, Int. Conf. (1997)

2. A. Elhadidy, M. Shaahid, Ren. Ene, 21 (2000)

3. S. Guo, Q. Liu, J. Sun, H. Jin, Ren. and Sus. Ene. Reviews, 91 (2018)

4. M. Jahangiri, A. Haghani, A. Raeisi, Ren. and Sus. Ene. Reviews, 99 (2019)

5. T. Kerdphol, Y. Qudaih, Y. Mitani, IEEE (2014)

6. B. Ceran, Q. Hassan, M. Jaszczur, K. Sroka, E3S Web of Con. 14 (2017)

7. P. Palej, H. Qusay, S. Kleszcz, R. Hanus, M. Jaszczur, Energy Policy Journal 22 (2019)

8. Q. Hassan, M. Jaszczur, J. Abdulateef, Journal of Physics: Conference Series 745 (2016)

9. Q. Hassan, M. Jaszczur, E. Przenzak, E3S Web of Conferences 14 (2017)

10. Q. Hassan, M. Jaszczur, M. Mohamed, K. Styszko, K. Szramowiat, J. Gołaś, E3S Web of Con. 10 (2016)

11. Q. Hassan, M. Jaszczur, Juste M. Serrano, R. Hanus, IOP Earth and Environmental Science 214 (2019)

12. M. Jaszczur, Q. Hassan, P. Palej, E3S Web of Conferences 113 (2019)

13. M. Jaszczur, J. Teneta, K. Styszko, Q. Hassan, P. Burzyńska, E. Marcinek, N. Łopian, Environmental Science and Pollution Research 26 (2019)

14. M. Jaszczur, Q. Hassan, M. Szubel, E. Majewska, Journal of Physics: Conference Series 1101 (2018)

15. M. Jaszczur, Q. Hassan, J. Teneta, K. Styszko, W. Nawrot, R. Hanus, MATEC Web of Conf. 240 (2018)

16. M. Jaszczur, Q. Hassan, J. Teneta, E. Majewska, M. Zych, MATEC Web of Conferences 240 (2018)

17. M. Jaszczur, Q. Hassan, J. Teneta, MATEC Web of Conferences MATEC Web of Con. 240 (2018)

18. Q. Huang, Y. Shi, Y. Wang, Ren. Ene. 76 (2015)

19. A. Nguyen, L. Crow, C. Elmore, IEEE 6 (2015)

20. B. Bahmani, R. Azizipanah, Inte. Ele. Pow. Ene. Sys. 56 (2014)

21. X. Chen, B. Gooi, M. Wang, IEEE 3 (2011)

22. C. Abbey, G. Joós, IEEE 24 (2008)

23. M. Jahangiri, R. Haghani, Ren. Eng. Rev. 99 (2019)

24. S. Borowy, M. Salameh, IEEE 9 (1994)

25. P. Kruangpradit, W. Tayati, Ren. Ene. 8 (1996)

26. J. Akerlund, J. Ottosson, IEEE 87 (1987)

27. E. Nogaret, G. Stavrakakis, C. Bonin, IEEE (1994)

28. Aeolos-H $1 \mathrm{~kW}$ wind turbine available at http://www.windturbinestar.com.

29. Schott ASI100 photovoltaic available at https://www.schott.com.

30. Generic: $1200 \mathrm{CH}$ inverters available at http://www.generic.com. 